\title{
Differential symptomatology and prevention of permanent complications dependent on localisation of osteochondroma
}

\author{
Przemysław Gałązka', Marika Reszczyńska-Domagała', Krzysztof Redloch², \\ Przemysław Ratajczak², Agata Marjańska ${ }^{3}$ Jan Styczyński ${ }^{3}$, Irena Daniluk-Matraś1 \\ 'Department of General and Oncological Surgery for Children and Adolescents, Ludwik Rydygier Collegium Medicum \\ in Bydgoszcz, Nicolaus Copernicus University in Torun, Antoni Jurasz University Hospital No. 1, Bydgoszcz, Poland \\ 2Department of Radiology and Imaging Diagnostics, Ludwik Rydygier Collegium Medicum in Bydgoszcz, \\ Nicolaus Copernicus University in Torun, Bydgoszcz, Poland \\ ${ }^{3}$ Department of Paediatrics, Haematology and Oncology, Ludwik Rydygier Collegium Medicum in Bydgoszcz, \\ Nicolaus Copernicus University in Torun, Antoni Jurasz University Hospital No. 1, Bydgoszcz, Poland
}

\section{ABSTRACT}

Osteochondroma is the most common benign bone tumour in children and usually occurs in the metaphyseal region of the long bones, being responsible for over $40 \%$ of all bone tumours and tumour-like lesions. The objective of this paper is the presentation of a series of cases of children with osteochondroma with different localisation and clinical presentation. Variability of localisation resulted in differential approach and prevention of permanent complications. Total surgical en bloc excision of the adjacent osteochondroma is considered as the treatment of choice. Symptoms related to an osteochondroma are usually relieved by the surgery. Major complications and local recurrence are rare. The general surgical indications for benign bone growths are cosmetic defect, exostosis in a location at risk to repetitive trauma, increased risk of the exostoses to fracture, neurological involvement, impairment of the articular range of motion, and suspicion of malignancy.

\section{KEY WORDS:}

osteochondroma, exostosis, benign bone tumour, children, surgery, complications.

\section{INTRODUCTION}

The overall incidence of bone tumours and tumour-like lesions of bone is 79.3 per 1,000,000 children, as was shown in long-term population-based analysis [1]. Incidence in boys is significantly higher than in girls: 90.7 vs. 67.3, respectively. Malignant tumours (osteosarcoma, Ewing sarcoma, chondrosarcoma) constitute $17.5 \%$ of cases, and non-malignant tumours the other $82.5 \%$ [1].
Osteochondroma is the most common benign bone tumour (Table 1) and usually occurs in the metaphyseal region (Fig. 1, according to [2]) of the long bones and is responsible for $44.4 \%$ of all bone tumours and tumour-like lesions [1], although their true incidence is unknown because many cases remain undiagnosed [3]. This tumour takes the form of a cartilage-capped bony outgrowth on the surface of the bone. The vast majority $(85 \%)$ of osteochondromas present as solitary, nonhe-

\section{ADDRESS FOR CORRESPONDENCE:}

Przemysław Gałązka, Department of General and Oncological Surgery for Children and Adolescents, Ludwik Rydygier Collegium Medicum in Bydgoszcz, Nicolaus Copernicus University in Torun, Antoni Jurasz University Hospital No. 1, 9 Marii Skłodowskiej-Curie St., 85-094 Bydgoszcz, Poland, e-mail: galazkaprzemek@hotmail.com 
TABLE 1. Benign bone tumours in children

\begin{tabular}{|l|l|}
\hline Group & Diseases \\
\hline $\begin{array}{l}\text { Benign } \\
\text { osteoid } \\
\text { tumours }\end{array}$ & $\begin{array}{l}\text { osteoma } \\
\text { osteoid osteoma } \\
\text { osteoblastoma }\end{array}$ \\
\hline $\begin{array}{l}\text { Benign } \\
\text { chondroid } \\
\text { tumours }\end{array}$ & $\begin{array}{l}\text { osteochondroma, exostosis osteocartilaginea } \\
\text { chondroma: enchondroma, chondroma } \\
\text { periostale } \\
\text { chondroblastoma benignum } \\
\text { fibroma chondromyxoides }\end{array}$ \\
\hline $\begin{array}{l}\text { Other benign } \\
\text {-tumours }\end{array}$ & $\begin{array}{l}\text { tumour gigantocellularis ossis, osteoclastoma } \\
\text { fibroma nonossificans }\end{array}$ \\
\hline $\begin{array}{l}\text { Tumour-like } \\
\text { lesions }\end{array}$ & $\begin{array}{l}\text { dysplasia polyostica fibrosa } \\
\text { cystis ossis unilocularis solitaria } \\
\text { cystis aneurysmatica ossis } \\
\text { granuloma eosinophyllicum } \\
\text { myositis ossificans } \\
\text { fibrous cortical defect }\end{array}$ \\
\hline
\end{tabular}

reditary lesions. Approximately $15 \%$ of osteochondromas occur as multiple lesions in the context of hereditary multiple osteochondromas, a disorder that is inherited in an autosomal dominant manner [4]. Slow progressive osteochondroma growth is the rule in skeletally immature patients, at times prompting surgical excision [5].

Solitary osteochondromas have a tendency to appear in long bones, especially the femur, humerus, tibia, spine, and hip, although every part of the skeleton can be affected [4]. Unusual locations of osteochondromas may include clavicular involvement with impaired shoulder mechanics, which results in painful shoulder, while another with pubic ramus involvement leads to obstructive urination symptoms and dysuria. Rare locations include scapula, fibular head with peroneal or tibial nerve compression, ischial ramus, or rib involvement [6].

Hereditary multiple osteochondromas are caused by gene mutations located either on chromosome 8q24.11-q24.13 (EXT1) or 11p11-12 (EXT2), while nonhereditary osteochondromas might present biallelic inactivation of the EXT1 locus (reviewed in [4]). Osteochondroma most commonly involves the metaphyses of the long bones, with a cartilage-capped bony projection on the external surface of a bone [6]. Osteochondromas develop in bones that are formed by endochondral ossification and result from displacement of the lateral portion of the growth plate, which then proliferates to the long axis of the bone [4]. The outer layer of the head of osteochondroma is composed of benign hyaline cartilage and is delineated peripherally by perichondrium. The cartilage has the appearance of a disorganised growth plate, which undergoes enchondral ossification and bone reconstruction [4].

The objective of this paper is the presentation of a series of cases of children with osteochondroma with different localisation and clinical presentation. Variability of localisation resulted in differential approach and preven-

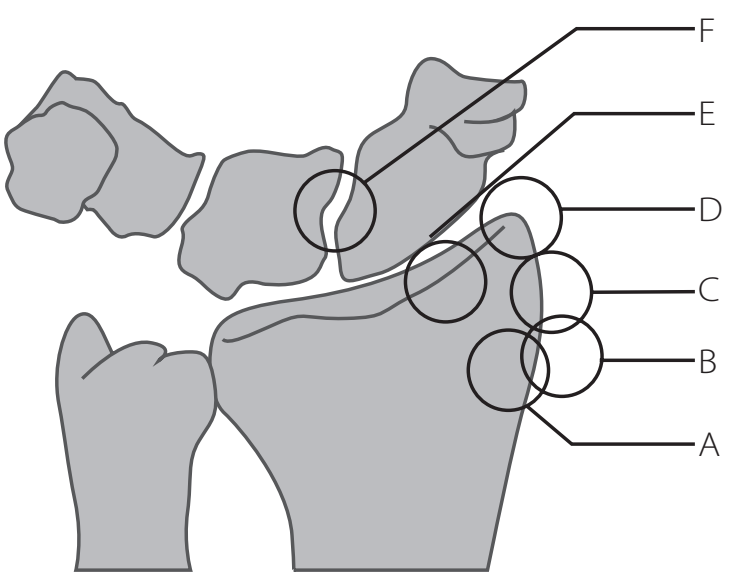

FIGURE 1. Classification of osteochondroma with respect to localisation

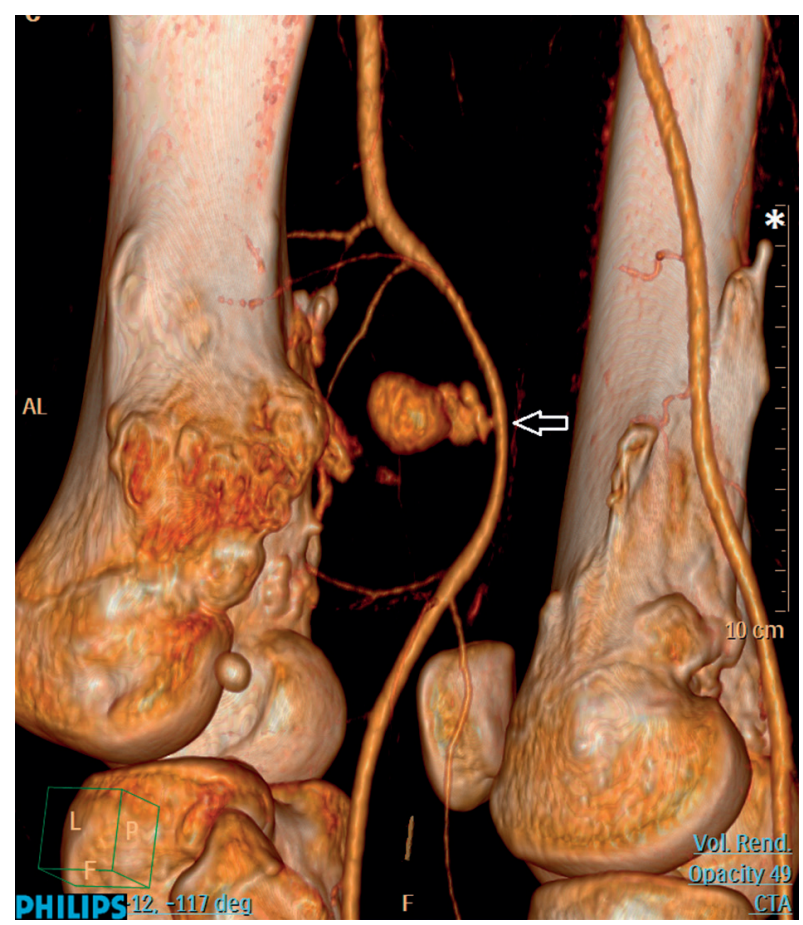

FIGURE 2. Preoperative angio-CT showing partial flow in the pseudoaneurysm in the left popliteal region. Arrow indicates point of artery disruption. Note another exostosis in the contralateral femoral bone $(*)$

tion of complications. We describe detailed management in specific clinical situations.

\section{CASE 1}

A 16-year-old boy with painful tumour of the posteromedial part of the distal femur, with no history of trauma. Multiple exostoses of both femoral bones were present in a conventional X-ray study. Ultrasound examination revealed partially thrombosed pseudoaneurysm, $75 \mathrm{~mm} \times 54 \mathrm{~mm} \times 105 \mathrm{~mm}$ in size, of the popliteal artery secondary to distal femur osteochondroma. Preoperative angio-CT (computed tomography) showed partial flow in the pseudoaneurysm in the left popliteal region. The point of artery disruption was clearly visible (Fig. 2). The 


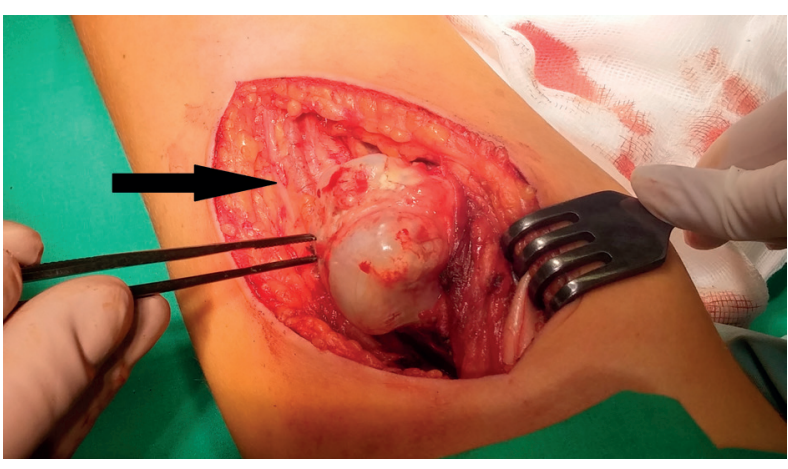

FIGURE 3. Intraoperative view of osseocartilaginous tumour in the medial portion of the right arm. Note stretched neuro-vascular bundle (arrow)
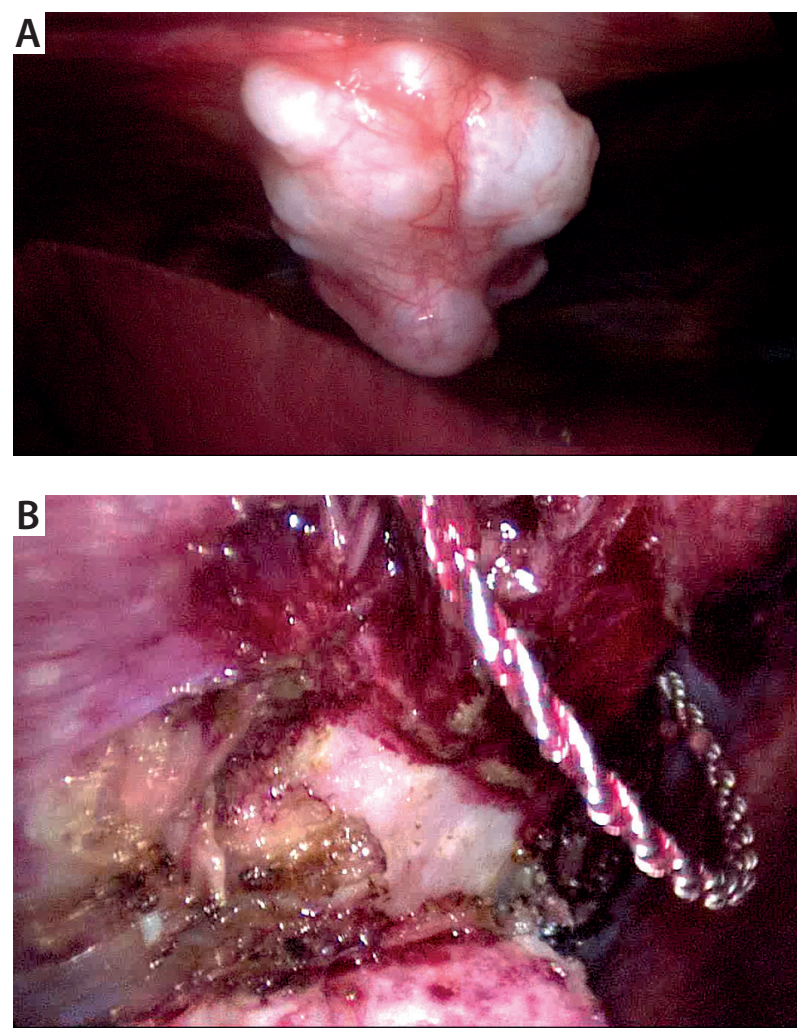

FIGURE 4. Thoracoscopic view of rib cartilaginous exostosis excision: A) an exophytic nature of the tumour was noted with the future possibility of lung contusion if not treated; B) Gigli saw usage for adequate partial rib resection

patient underwent surgery with tumour excision and removal of $300 \mathrm{ml}$ of blood from the pseudoaneurysm. The popliteal artery wall was repaired at the level of the adductor muscles canal. The postoperative course was uneventful, and the patient regained normal activity during four years of follow-up. There was no sign of malignant transformation on histopathological examination of bone. Osteochondroma was the final diagnosis.

\section{CASE 2}

A 14-year-old boy with symptoms of weakness of the right upper limb for more than one year followed by development of a $5-\mathrm{cm}$ tumour in the medial portion of the proximal humerus. Pain, decreased range of movement, or paraesthesia were not reported. During surgery, stretching of the humeral vessels and median nerve was noted and corrected (Fig. 3). No regrowth or dysfunction were observed during eight months of follow-up after the operation. In pathology examination osteochondroma was diagnosed.

\section{CASE 3}

A 13-year-old boy, admitted to the hospital for acute pain in the left hypochondrium. Due to splenomegaly, haematological and immunological diseases were excluded in differential diagnosis. Chest X-ray revealed a round $3 \mathrm{~cm}$ area, and CT scan confirmed the presence of a sixth rib tumour located on the internal side close to junctura cartilaginea. Additionally, a soft tissue reaction was found. The tumour was successfully radically resected with a thoracoscope-assisted segmental rib resection, and no complications occurred during six months of follow-up (Fig. 4). Histopathological examination confirmed the diagnosis of osteochondroma.

\section{DISCUSSION}

We present three cases of osteochondroma with different localisations, different symptoms, and different profiles of potential complications. Osteochondroma (exostosis) is a very common bone tumour. Complications, such as exostosis degeneration, orthopaedic complications, or nerve compression, occur in $4 \%$ of cases; however, vascular complications such as pseudoaneurysm are exceptionally rare. Pseudoaneurysm is most often located on the popliteal artery [7]. Pseudoaneurysm results from an arterial injury due to exostosis. Its mechanism of development is still unknown because it is usually asymptomatic. The vascular disease genesis is due to repeated exercises, such as knee flexion, which could chronically affect the popliteal artery and produce an casual defect followed by a pseudoaneurysm. Pain, oedema, and pulsating mass are the most frequent clinical signs of pseudoaneurysm. The treatment of vascular complication is surgical, at the same time as the bone tumour. Surgical treatment of exostosis vascular complications is recommended as an urgent procedure to prevent the occurrence of irreversible damage [8].

Until 2016, a total of 101 cases arterial pseudoaneurysms associated with osteochondromas were reported worldwide, with a masculine preponderancy in $86 \%$. Popliteal artery was the most commonly injured vessel in $77 \%$. The treatment was open surgery with vascular repair and optimal exostectomy. Arterial repair was performed with saphenous vein grafting or lateral suture. Postoperative courses were uneventful in the vast majority of cases $[9,10]$. The value of the use of arteriography to confirm 
the diagnosis is limited to the benefit of non-invasive radiological methods because endovascular treatment is not relevant in the setting of osteochondroma-induced arterial pseudoaneurysm [9].

Nerve compressions due to osteochondromas are extremely rare. Immediate treatment is mandatory to regain the best possible recovery, thus all patients with peripheral nerve compression due to an osteochondroma should undergo surgery. Preoperative electromyographic examinations and radiographic evaluation, consisting of MRI and CT to provide optimal information about the lesion, are crucial. Performing nerve decompression first and en bloc resection of osteochondroma consecutively in a multidisciplinary fashion is strongly recommended to avoid peripheral nerve injury [11].

Two per cent of osteochondromas grow in the chest wall $[12,13]$. On the other hand, only $10 \%$ of rib tumours are benign, and osteochondromas account for half of them [14]. These tumours typically begin to grow before puberty and continue until bone maturation is reached. Costal osteochondromas tend to grow into the chest cavity, and such lesions are rarely exophytic [14]. Most costal lesions are asymptomatic, but life threatening conditions such as pneumothorax through puncture, laceration, or friction from chest wall movement during breathing can occur $[12,13]$. The consequent change in intrapleural pressure and possible lung collapse can cause an emergency medical situation.

\section{CONCLUSIONS}

In conclusion, symptoms related to osteochondroma are usually relieved by surgery. Major complications and local recurrence are rare. The general surgical indications for benign bone growths are cosmetic defect, exostosis in a location at risk of repetitive trauma, increased risk of the exostoses to fracture, neurological involvement, impairment of the articular range of motion, and suspicion of malignancy. Total surgical en bloc excision of the adjacent osteochondroma is considered as the treatment of choice $[11,15]$.

\section{DISCLOSURE}

The authors declare no conflict of interest.

\section{REFERENCES}

1. van den Berg H, Kroon HM, Slaar A, Hogendoorn P. Incidence of biopsy-proven bone tumors in children: a report based on the Dutch pathology registration "PALGA". J Pediatr Orthop 2008; 28: 29-35.

2. Zlotolow DA, Mills J, Ezaki M, et al. Epiphyseal osteochondromas of the upper limb: a report of 7 cases. J Pediatr Orthop 2012; 32: 541-546.

3. Hill CE, Boyce L, van der Ploeg ID. Spontaneous resolution of a solitary osteochondroma of the distal femur: a case report and review of the literature. J Pediatr Orthop B 2014; 23: 73-75.
4. Kitsoulis P, Galani V, Stefanaki K, et al. Osteochondromas: review of the clinical, radiological and pathological features. In Vivo 2008; 22: 633-646.

5. Passanise AM, Mehlman CT, Wall EJ, Dieterle JP. Radiographic evidence of regression of a solitary osteochondroma: a report of 4 cases and a literature review. J Pediatr Orthop 2011; 31: 312-316.

6. Gökkuş K1, Atmaca H, Sağtaş E, et al. Osteochondromas originating from unusual locations complicating orthopedic discipline: case series. Eklem Hastalik Cerrahisi 2015; 26: 100-109.

7. Antonio ZP, Alejandro RM, Luis MR, Jose GR. Femur ostochondroma and secondary pseudoaneurysm of the popliteal artery. Arch Orthop Trauma Surg 2006; 126: 127-130.

8. Nasr B, Albert B, David CH, et al. Exostoses and vascular complications in the lower limbs: two case reports and review of the literature. Ann Vasc Surg 2015; 29: 1315.e1317-1315.e1314.

9. Raherinantenaina F, Rakoto-Ratsimba HN, Rajaonanahary TM. Management of extremity arterial pseudoaneurysms associated with osteochondromas. Vascular 2016; 24: 628-637.

10. Bottner F, Rodl R, Kordish I, et al. Surgical treatment of symptomatic osteochondroma. A three- to eight-year follow-up study. J Bone Joint Surg Br 2003; 85: 1161-1165.

11. Gocmen S, Topuz AK, Atabey C, et al. Peripheral nerve injuries due to osteochondromas: analysis of 20 cases and review of the literature. J Neurosurg 2014; 120: 1105-1112.

12. Kameda T, Makino T, Sakai T, et al. Asymptomatic costal exostosis with thickening in the pericardium: a case report. J Cardiothorac Surg 2016; 11: 36.

13. Imai K, Suga $Y$, Nagatsuka $Y$, et al. Pneumothorax caused by costal exostosis. Ann Thorac Cardiovasc Surg 2014; 20: 161-164.

14. Marino-Nieto J, Lugo-Vicente H. Rib osteochondroma in a child: case report and review of literature. Bol Asoc Med P R 2011; 103: 47-50.

15. Abdel MP, Papagelopoulos PJ, Morrey ME, et al. Surgical management of 121 benign proximal fibula tumors. Clin Orthop Relat Res 2010; 468: 3056-3062. 